\title{
Detección de anticuerpos séricos contra Toxoplasma gondii (Nicolle y Manceaux, 1909) en llamas (Lama glama Linneaus, 1758) y alpacas (Lama pacos Linneaus, 1758 ) de Chile\#
}

\author{
Sera antibodies to Toxoplasma gondii in lamas and alpacas of Chile \\ A N Patitucci", M J Pérez, G Barril, C M Cárcamo, A Muñoz \\ Escuela de Medicina Veterinaria, Universidad Católica de Temuco, Chile.
}

\section{SUMMARY}

\begin{abstract}
Sera samples from 113 llamas (Lama glama) and 127 alpacas (Lama pacos) from the IX and V Regions, respectively, of Chile were tested for Toxoplasma gondii antibodies. The modified agglutination test (MAT) was used in both species and titers 1:25 were considered diagnostically significant based in previously published data. Sera from 49 lamas (43.3\%) and 15 alpacas (11.8\%) were positive to T. gondii. Percentaje seropositivity in serum dilutions of $1: 25,1: 50,1: 500$ and $1: 5000$ was $17.6 \% ; 7.9 \% ; 14.1 \%$ and $3.5 \%$ in lamas and $0 \% ; 2.3 \% ; 0.7 \%$ and $8.6 \%$ in alpacas, respectively. The rather low prevalence in alpacas may be associated with geographical conditions, management practices or contacts with cats rather than different species susceptibility. As expected, older animals showed higher reactivity of $T$. gondii than young animals.
\end{abstract}

Palabras clave: Toxoplasma gondii, llamas, alpacas.

Key words: Toxoplasma gondii, lamas, alpacas.

\section{INTRODUCCION}

Existen cuatro especies de camélidos sudamericanos: dos de ellas, la llama (Lama glama Linneaus 1758) y la alpaca (Lama pacos Linneaus 1758) son domésticos, mientras que la vicuña (Vicugna vicugna Molina 1792) y el guanaco (Lama guanicoe Müller 1776) son de vida silvestre (Fernández-Baca 1991, 1993). Llamas y alpacas fueron domesticadas durante el imperio Inca (siglo XV) cuya crianza estuvo destinada para el uso de su carne, lana y cuero (Raggi 2000). Aún hoy llamas y alpacas juegan un rol importante en la economía de una gran parte de la población de la región andina, especialmente de Perú y Bolivia (Fernández-Baca 1993).

En Chile, los camélidos sudamericanos, y particularmente las llamas y las alpacas, pueden encontrarse en el altiplano de la I Región de Tarapacá, a una altura de 4.000 metros sobre el nivel del mar (Valenzuela y col 1998). Sin embargo, en los últimos años existe un interés por introducir camélidos domésticos en las zonas centro y sur del país, donde varios centros de cría intentan rescatar el patrimonio genético existente mediante reproducción y selección de los mejores ejemplares (Sepúlveda y Risopatron 1993).

En estas circunstancias las enfermedades en los ani-

Aceptado: 20.12.2005

* Fax: 45 205570, apatituc@uct.cl, CC:15-D.

\# Proyecto DIUC, N²003-3-01 males cobran importancia tanto para la producción como para la conservación de las especies (Ramírez 1998). Entre ellas, las enfermedades parasitarias de los camélidos constituyen uno de los problemas de mayor importancia económica, ya que disminuyen la calidad y producción de fibra, de carne y de leche (Guerrero y Leguía 1987, Guerrero y col 1994). Se sabe que Toxoplasma gondii es un patógeno primario de los camélidos sudamericanos (Leguía y col 1988, Dubey y col 1992, Jarvinen y col 1999).

La toxoplasmosis es una infección de distribución mundial, que afecta a muchas especies animales de sangre caliente, incluyendo al hombre (Dubey y Beattie 1988). T. gondii, el agente causante de la enfermedad, es un parásito protozoario, perteneciente al phylum Apicomplexa y a la familia Sarcocystidae, junto con Neospora caninum y Sarcocystis spp (Buxton 1998, Buxton y Henderson 1999). T. gondii, causa mortalidad perinatal y neonatal en ovejas, cabras, seres humanos y otras especies animales (Dubey 1982, Dubey y Carpenter 1993, Buxton 1998, Buxton y Henderson 1999). En camélidos, este parásito ha sido implicado como causa de muerte embrionaria, aborto, malformaciones congénitas y nacimiento de crías muertas o débiles que mueren poco tiempo después de nacidas (Guerrero y Leguía 1987, Leguía y col 1988, Dubey y col 1992, Jarvinen y col 1999).

La enfermedad se puede diagnosticar, mediante la detección del parásito o, en forma indirecta, detectando anticuerpos específicos contra este, a través de pruebas 
serológicas (Acha y Szyfres 1986). En Chile, escasos trabajos (Gorman y col 1999, Rojas y col 1989) informan de la enfermedad en estos animales, por lo que se decidió realizar el presente estudio cuyo objetivo fue determinar la presencia de infección de $T$. gondii en llamas y alpacas, mediante la determinación de anticuerpos séricos utilizando el método de aglutinación (MAT).

\section{MATERIAL Y METODOS}

Considerando una prevalencia estimada de la enfermedad de 16\% (Gorman y col 1999), una especificidad de $90,3 \%$, una sensibilidad de $82,9 \%$ del MAT (Dubey y col 1995) y una población de aproximadamente 300 animales en cada establecimiento, el tamaño de muestra calculado por especie fue de 96 animales (Cannon y Roe 1982). Considerando una posible pérdida de muestras se obtuvieron 113 sueros de llamas y 127 de alpacas.

Las muestras de sangre de las llamas se obtuvieron de un criadero ubicado en la IX Región del país, durante la época de primavera. Las muestras fueron seleccionadas por conveniencia. Todos los animales fueron hembras de edades que variaron entre 1 y 9 años. Los animales fueron nacidos y criados en el mismo establecimiento, alimentados a base de pasturas naturales con suplemento en las épocas de escasez de forrajes. En el criadero existía población estable de gatos, los cuales eran mantenidos para el control de los roedores.

Los sueros de las alpacas se obtuvieron de un criadero ubicado en la V Región. La totalidad de los animales estudiados provenían de la precordillera andina de la zona norte del país, permaneciendo en el criadero por 2 a 4 meses para luego ser exportadas a USA y/o Europa. Los animales fueron hembras de edades entre 1 a 5 años. Estos animales se encontraban confinados en pequeños corrales y eran alimentados con heno de alfalfa. No existía en el establecimiento población estable de gatos domésticos.

Ambos establecimientos poseían supervisión veterinaria, encontrándose todos los animales estudiados clínicamente sanos al momento de tomar las muestras.

Los sueros se obtuvieron por separación a las 24 horas posteriores a la toma de las muestras de sangre. Dichos sueros se almacenaron a $-20^{\circ} \mathrm{C}$ hasta el momento de su análisis.

Para la detección de los anticuerpos se utilizó el "test" modificado de aglutinación (MAT) (Desmonts y Remington 1980, Dubey y Desmonts 1987), el cual emplea trofozoitos de $T$. gondii completos fijados en formalina como antígeno* con el agregado de mercaptoetanol y solución colorante de Azul de Evans. La reac-

Donado por Dr. Dubey JP., Parasite Biology, Epidemiology and Systematics Laboratory. USDA. Beltsville, Maryland 20705-2350, USA. ción de aglutinación se realizó en microplacas de 96 pocillos de fondo redondo. Para el procesamiento, cada suero se diluyó en 1:25; 1:50, 1:500 y 1:5000 en solución salina tamponada (PBS pH 7.2). Los sueros y la preparación antigénica fueron mezclados e incubados a $37^{\circ} \mathrm{C}$ durante 24 horas. Para la lectura se consideró que la presencia de anticuerpos séricos produce la aglutinación en suspensión de los parásitos, lo cual es visible macroscópicamente en el fondo de las microplacas. La ausencia de anticuerpos produce la sedimentación en un "botón azul" en el fondo de las micro-placas. Con cada "set" de sueros procesados se incluyeron sueros controles positivos y negativos.

Las diferencias por edades en las especies fueron analizadas estadísticamente mediante chi cuadrado.

\section{RESULTADOS Y DISCUSION}

Del total de 113 sueros de llamas estudiados, 49 $(43,3 \%)$ de ellas presentaron anticuerpos contra T. gondii, mientras que 15 de las $127(11,8 \%)$ alpacas fueron positivas (cuadro 1). El número de animales positivos en las diluciones $1 / 25 ; 1 / 50 ; 1 / 500 ; 1 / 5000$ fue de $20(17,6 \%)$; $9(7,9 \%) ; 16(10,6 \%) ; 4(3,5 \%)$ en las llamas y de $0(0 \%)$; $3(2,3 \%) ; 1(0,7 \%) ; 11(8,6 \%)$ en las alpacas respectivamente (cuadro 1 ).

En estudios similares realizados en el norte del país se detectó un $25,1 \%$ de seropositividad en llamas (Rojas y col 1989) y 16,3\% en alpacas (Gorman y col 1999). Ambos trabajos utilizaron la técnica de Hemaglutinación Indirecta (HAI). Valores mayores han sido encontrados en llamas (34,7\%) en Estados Unidos (Dubey y col 1992), utilizando el MAT como prueba de análisis y en camellos (Camelus dromedarios) (67\%) en las planicies del Este medio de Sudán (Elamin y col 1992).

La transmisión, y subsecuentemente la tasa de infección de la toxoplasmosis en una especie de hospedador, depende de múltiples factores, incluidos la proximidad con los gatos domésticos, condiciones climáticas y el tipo de suelo (Dubey y Beattie 1988, Elamin y col 1992). Se

Cuadro 1. Número y porcentaje de llamas y alpacas con presencia de anticuerpos séricos contra $T$. gondii detectados mediante la técnica MAT en las diferentes diluciones procesadas. Number of lamas and alpacas with antibodies against $T$. gondii detected by the MAT test with different dilutions.

\begin{tabular}{|c|c|c|c|c|c|c|}
\hline \multirow[t]{2}{*}{ Especie } & \multicolumn{4}{|c|}{ Diluciones MAT } & \multirow{2}{*}{ Positivos } & \multirow[t]{2}{*}{ Total } \\
\hline & $1 / 25$ & $1 / 50$ & $1 / 500$ & $1 / 5000$ & & \\
\hline $\begin{array}{l}\text { Llamas } \\
\%\end{array}$ & $\begin{array}{c}20 \\
(17,6)\end{array}$ & $\begin{array}{c}9 \\
(7,9)\end{array}$ & $\begin{array}{c}16 \\
(10,6)\end{array}$ & $\begin{array}{c}4 \\
(3,5)\end{array}$ & $\begin{array}{c}49 \\
(43,4)\end{array}$ & 113 \\
\hline $\begin{array}{l}\text { Alpacas } \\
\%\end{array}$ & $\begin{array}{c}0 \\
(0)\end{array}$ & $\begin{array}{c}3 \\
(2,3)\end{array}$ & $\begin{array}{c}1 \\
(0,7)\end{array}$ & $\begin{array}{c}11 \\
(8,6)\end{array}$ & $\begin{array}{c}15 \\
(11,8)\end{array}$ & 127 \\
\hline $\begin{array}{l}\text { Total } \\
\%\end{array}$ & 20 & 12 & 17 & 15 & $\begin{array}{c}64 \\
(26,7)\end{array}$ & 240 \\
\hline
\end{tabular}


piensa que la adquisición de la infección con Toxoplasma en camélidos ocurriría mediante la ingestión o inhalación de ooquistes esporulados, que son diseminados por felinos al ambiente (Elamin y col 1992). Aun cuando el contacto estrecho de gatos con camélidos puede ser difícil, la infección puede ocurrir a través de las pasturas contaminadas con heces de gatos (Leguía y col 1988, Fernández-Baca 1991, 1993, Zenner 1998). Estos factores podrían ser explicativos del porcentaje mayor en llamas, ya que estos animales convivían con felinos en las inmediaciones. En el caso de las alpacas, el menor porcentaje de infección obtenido en este estudio (11,8\% versus $43,3 \%$ ) puede ser explicado por la procedencia de los animales, dado que en la precordillera andina existirían menores posibilidades de infección, lográndose una prevalencia cercana al de un estudio realizado anteriormente que fue de $16 \%$ (Gorman y col 1999). Por otro lado, el período de confinamiento al que fueron sometidas las alpacas en el predio de la $\mathrm{V}$ Región previo a la extracción de muestra fue breve ( 1 a 2 meses), no existiendo una población felina estable en él.

Las edades de las alpacas muestreadas variaban de 1 a 5 años y las llamas entre 1 y 9 años. Para comparar el porcentaje de positivos por edades se dividieron los animales en dos grupos ( $\leq 3$ años $y \geq 3$ años) de acuerdo al manejo reproductivo de las hembras (Ponzoni 1996). En alpacas $\leq 3$ años se encontraron 5 positivas de 80 y 10 de 47 en las $\geq 3$ años $\left(\chi^{2}=5,056, P=0,0245\right)$ En llamas sólo se pudo obtener información relacionada con la edad en 100 animales y la positividad se distribuyó en: $\leq 3$ años 3 positivas de 19 y en $\geq 3$ años 43 de $81\left(\chi^{2}=7,182, \mathrm{P}=0,0074\right)$. Como se esperaba, en ambas especies el porcentaje de infección aumentaba al aumentar la edad. La prevalencia de $T$. gondii se incrementa con la edad, ya que los animales de mayor edad tienen más oportunidad de acceso al agente patógeno (Leguía y col 1988).

Todos los animales estudiados fueron hembras. No existen en la literatura datos que indiquen diferencias por sexo en ninguna especie de las susceptibles a $T$. gondii (Dubey y Beattie 1988, Dubey y col 1992).

Existen diferentes maneras de detectar la infección por este parásito. Así, T. gondii puede ser aislado de pacientes por inoculación de animales y por cultivo de tejidos (Dubey 1998, Lüders y col 1999). Por otro lado, existen varias pruebas serológicas que pueden ser utilizadas para la detección de anticuerpos contra $T$. gondii como son: Sabin y Feldman "dye test” (DT), Hemaglutinación indirecta (IHA), inmunofluorescencia de anticuerpos indirecta (IFA), test modificado de aglutinación (MAT), aglutinación en látex (LA), enzima inmunoensayo (ELISA) y fijación de complemento (CF) (Dubey y col 1987, Dubey 1998). El MAT es usado para la detección de anticuerpos IgG contra T. gondii (Dubey y col 1987, Apt 1988, Dubey 1998, Hove y Dubey 1999) y es considerado uno de los "test" más específicos $(90,3 \%)$ y sen- sibles $(82,9 \%)$ para la detección de infección de T. gondii en animales (Dubey y col 1987, 1998, Dubey 1996). Por otro lado, se ha demostrado que no produce reacciones cruzadas con otros parásitos relacionados o no relacionados (Dubey y col 1987, 1996, Hove y Dubey 1999). La dilución 1:25 fue seleccionada como indicativa de infección por $T$. gondii, basado en la experiencia de este método al ser empleado con sueros de otros animales (Wilson y col 1990, Dubey 1998, Hove y Dubey 1999).

$T$. gondii afecta a diferentes animales de sangre caliente, incluido el hombre. Este parásito causa enfermedad clínica que incluye infección congénita, pérdida reproductiva y mortalidad perinatal (Dubey y Beattie 1988). El parásito ha sido reportado como agente causal de abortos en ovinos, caprinos y también en llamas (Cheney y Allen 1989, Rojas 1990). Aunque no existían antecedentes clínicos de la enfermedad en los establecimientos estudiados, su potencial implicancia en este tipo de patología debería ser considerada sobre la base de los resultados del presente trabajo que demuestran que llamas y alpacas del centro-sur de Chile poseen evidencia serológica de infección por $T$. gondii.

\section{RESUMEN}

Se obtuvieron 113 sueros de llamas y 127 de alpacas de criaderos ubicados en la IX y V Regiones del país respectivamente para determinar la presencia de infección de T. gondii. Para el análisis de los sueros se utilizó el "test" modificado de aglutinación (MAT) a diluciones 1:25; 1:50, $1: 500 ; 1: 5000$. Del total de 113 sueros de llamas estudiados 49 $(43,3 \%)$ de ellas presentaron anticuerpos contra $T$. gondii, mientras que en las alpacas 15 de las 127 (11,8\%) fueron positivas. El número de animales positivos en las diluciones $1 / 25 ; 1 / 50 ; 1 / 500 ; 1 / 5000$ fue de $20(17,6 \%) ; 9(7,9 \%) ; 16$ $(10,6 \%) ; 4(3,5 \%)$ en las llamas, respectivamente. En las alpacas los valores fueron de $0(0 \%) ; 3(2,3 \%) ; 1(0,7 \%) ; 11(8,6 \%)$, respectivamente. Aunque no existen antecedentes clínicos de la infección en los establecimientos estudiados, su potencial implicancia en este tipo de patología debería ser considerada a base de los resultados del presente trabajo que demuestra que llamas y alpacas del centro-sur de Chile son reaccionantes a la infección por $T$. gondii.

\section{REFERENCIAS}

Acha NP, B Szyfres. 1986. Zoonosis y enfermedades transmisibles comunes al hombre y a los animales. OPS/OMS. $989 \mathrm{p}$.

Apt W. 1988. Avances en el diagnóstico serológico de la toxoplasmosis. Parasitol al día 12, 33-39.

Buxton D. 1998. Protozoan infections (Toxoplasma gondii, Neospora caninum and Sarcocystis spp) in sheep and goats: recent advances. Vet Res 29, 289-310.

Buxton D, D Henderson. 1999. Infections abortion in sheep. In: Practice. July/August. 360-368.

Cannon RM, RT Roe. 1982. Livestock Disease survey: a field manual for veterinarians. Australian Government Publishing Service, Canberra. 
Cheney JM, GT Allen. 1989. Parasitism in Llamas. Vet Clin N A Food Anim Pract 5(1), 217-225

Desmonts G, JS Remington. 1980. Direct Agglutination test for diagnosis of Toxoplasma infection: method for increasing sensitivity and specificity. J Clin Microb 11, 562-568.

Dubey JP. 1982. Repeat transplacental transfer of Toxoplasma gondii in dairy goats. J Amer Vet M Assoc 180, 1220-1221.

Dubey JP. 1996. Infectivity and pathogenicity of Toxoplasma gondii oocysts for cats. J Parasit Vol. 82, 957-961.

Dubey JP. 1998. Toxoplasma gondii oocyst survival defined temperatures. J Parasit 862-865.

Dubey JP, CP Beattie. 1988. Toxoplasmosis of animals and man. C R C Press, Boca Ratón, Florida. Pp 220.

Dubey JP, JL Carpenter. 1993. Neonatal toxoplasmosis in littermate cats. J Amer Vet M Assoc 203, 1546-1549.

Dubey JP, G Desmonts. 1987. Serological responses of equids fed Toxoplasma gondii oocysts. Equine Vet J 19, 337-339.

Dubey JP, HPA Hughes, HS Lillehoj, HR Gamble, BL Munday. 1987. Placental transfer of specific antibodies during ovine congenital toxoplasmosis. Amer J Vet Res 48, 474-476

Dubey JP, LG Rickard, GL Zimmerman, DM Mulrooney. 1992. Seroprevalence of Toxoplasma gondii in Llamas (Lama glama) in the northwest USA. Vet Parasit 44, 295-298.

Dubey JP, P Thulliez, RM Weigel, CD Andrews, P Lind, EC Powell. 1995. Sensitivity and specificity of various serologic tests for detection of Toxoplasma gondii infection in naturally infected sows. Amer J Vet Res 56, 1030-1036.

Dubey JP, CD Andrews, P Lind, OCH Kwok, P Thulliez, JK Lunney. 1996 Antibody responses measured by various serologic test in pigs orally inoculated with low numbers of Toxoplasma gondii oocysts. Amer J Vet Res 57, № 12 , 1733-1737.

Dubey JP, S Romand, M Hilali, OCH Kwok, P Thulliez. 1998. Seroprevalence of antibodies to Neospora caninum and Toxoplasma gondii in water buffaloes (Bubalus bubalis) from Egypt. Intern J Paras 28, 527-529.

Elamin EA, S Elias, A Daugschies, M Rommel. 1992. Prevalence of Toxoplasma gondii antibodies in pastoral camels (Camelus dromedarius) in the Butana plains, midEastern Sudan. Vet Parasit 43, 171-175.

Fernández-Baca S. 1991. Avances y Perspectivas del conocimiento de los Camélidos Sudamericanos. Organización de las Naciones Unidas para la Agricultura y la Alimentación. Oficina Regional de la FAO para América Latina y el Caribe. Pp 429.

Fernández-Baca S. 1993. Manipulation of reproductive functions in male and female new world camelids. Anim Reprod Sci 33, 307-323.

Gorman T, JP Arancibia, M Lorca, D Hird, H Alcaíno. 1999. Seroprevalence of Toxoplasma gondii infection in sheep and alpacas (Lama pacos) in Chile. Prev Vet Med 40, 143-149.
Guerrero O, M Chinchilla, G Catarinella, A Castro, E Abrahams. 1994. Patrón de tránsito intestinal de los ooquistes de Toxoplasma gondii en rata, ratón y hamster. Parasitol al día 18, 71-76.

Guerrero C, G Leguia. 1987. Enfermedades Infecciosas y Parasitarias de las Alpacas. Revista de Camélidos Sudamericanos. Lima-Perú № 4 . Pp 82.

Hove T, JP Dubey. 1999. Prevalence of Toxoplasma gondii antibodies in sera of domestics pigs and some wild game species from Zimbabwe. J Parasit 85, 372-373.

Jarvinen JA, JP Dubey, GC Althouse. 1999. Clinical and Serologic Evaluation of Two Llamas (Lama glama) infected with Toxoplasma gondii during gestation. J Parasit $85,142-144$.

Leguía G, H Samame, C Guerrero, M Rojas, A Núñez. 1988. Prevalencia de anticuerpos contra Toxoplasma gondii en Alpacas. Revista de Camélidos Sudamericanos. Lima- Perú № 6. $\mathrm{Pp} 58$.

Lüder CG, M Giraldo-Velásquez, M Sendtner, U Gross. 1999. Toxoplasma gondii in primary rat CNS cells: differential contribution of neurons, astrocytes, and microglial cells for the intracerebral development and stage differentiaton. Exp Parasit 93, 23-32.

Ponzoni RW. 1996. Manual de prácticas de manejo de alpacas y llamas. Cuaderno técnico № 130, F.A.O.

Raggi LA. 2000. Advances in research and management of llamas (Lama glama) and alpaca (Lama pacos) in Chile. Ciencia e Investigación agraria 27, 27-37.

Ramírez A. 1998. Diagnóstico y control de enfermedades en camélidos sudamericanos. Publicación Técnica. Facultad de Medicina Veterinaria, Universidad Nacional Metropolitana San Marcos. Perú. N 34. Pp 88.

Rojas M. 1990 Parasitismo de los Rumiantes Domésticos. Terapia, Prevención y Modelos para su Aprendizaje. Serie Medicina. Editorial Maijosa. Lima-Perú. Pp 383.

Rojas M, I Lobato, C Montalvo. 1989. Prevalencia de Toxoplasma gondii en Camélidos Sudamericanos. Resumen $12^{\mathrm{a}}$ reunión científica anual del APPA-Perú. Pp 97.

Sepúlveda N, J Risopatrón. 1993. Antecedentes sobre la Ganadería de Camélidos en el sur de Chile. Arch Med Vet 25, 187-191.

Valenzuela G, M Leiva, I Quintana. 1998. Estudio Epidemiológico de Nemátodos Gastrointestinales en praderas pastoreadas por alpacas (Lama pacos) en Valdivia, Chile. Arch Med Vet 30, 79-90.

Wilson M, DA Ware, DD Juranek. 1990. Serologic aspects of toxoplasmosis. J Amer Vet Med Assoc 196, 277-281.

Zenner L. 1998. Toxoplasma gondii: kinetics of the dissemination in the host tissues during the acute phase of infection of mice and rats. Exp Parasit 90, 86-94. 